\section{ADAPTATIONS IN GASTROINTESTINAL PHYSIOLOGY AFTER SLEEVE GASTRECTOMY AND ROUX-EN-Y} GASTRIC BYPASS

Nele Steenackers ${ }^{1}$, Tim Vanuytsel ${ }^{2}$, Patrick Augustijns ${ }^{3}$, Jan Tack ${ }^{2}$, Ann Mertens $^{1}$, Matthias Lannoo ${ }^{4}$, Bart Van der Schueren ${ }^{1}$ and Christophe Matthys ${ }^{1}$

${ }^{1}$ Clinical and Experimental Endocrinology, Department of Chronic Diseases, Metabolism and Ageing, KU Leuven, Leuven, Belgium; 'Translational Research Center for Gastrointestinal Disorders, Department of Chronic Diseases, Metabolism and Ageing, KU Leuven, Leuven, Belgium. ${ }^{3}$ Drug Delivery and Disposition, Department of Pharmaceutical and Pharmacological Sciences, KU Leuven, Leuven, Belgium; ${ }^{4}$ Department of Abdominal Surgery, University Hospitals Leuven, Leuven, Belgium.

\section{Contact information authors:}

Nele Steenackers, MSc

Clinical and Experimental Endocrinology

O\&N I Herestraat 49 - box 902

3000 Leuven, Belgium

Nele.steenackers@kuleuven.be

+3216344913

\section{Assistant professor Tim Vanuytsel, PhD}

Translational Research in Gastrolntestinal Disorders

O\&N I Herestraat 49 - box 701

3000 Leuven, Belgium

Tim.vanuytsel@kuleuven.be

+3216373943

Full professor Patrick Augustijns, PhD

Drug Delivery and Disposition

O\&N II Herestraat 49 - box 921

3000 Leuven, Belgium

Patrick.augustijns@kuleuven.be 
Full professor Jan Tack, PhD

Translational Research in Gastrolntestinal Disorders

O\&N I Herestraat 49 - box 701

32

3000 Leuven, Belgium

33

Jan.tack@kuleuven.be

+3216344225

Assistant professor Ann Mertens, PhD

Clinical and Experimental Endocrinology

UZ Herestraat 49 - box 700344

3000 Leuven, Belgium

Ann.mertens@kuleuven.be

40

+3216346993

Assistant professor Matthias Lannoo, PhD

42 Clinical and Experimental Endocrinology

UZ Herestraat 49 - box 700344

443000 Leuven

Matthias.lannoo@kuleuven.be

$46+3216375200$

Associate professor Bart Van der Schueren, PhD

Clinical and Experimental Endocrinology

49 UZ Herestraat 49 - box 700344

503000 Leuven, Belgium

51 Bart.vanderschueren@kuleuven.be

$52+3216376279$ 
53 Corresponding author: Associate professor Christophe Matthys, PhD

$54 \quad$ Clinical and Experimental Endocrinology

55

UZ Herestraat 49 - box 700344

56

3000 Leuven, Belgium

57 Christophe.matthys@kuleuven.be

$58+3216342655$

59 Running title: Adaptations in Gastrointestinal Physiology After Bariatric Surgery

60 Key words: Bariatric Surgery, Sleeve Gastrectomy, Gastric Bypass, Upper Gastrointestinal Tract, 61 Lower

Gastrointestinal

Tract 


\section{Abstract}

64 The growing obesity epidemic explains the increased demand for bariatric and metabolic surgery. To date, Sleeve Gastrectomy (SG) and Roux-en-Y Gastric Bypass (RYGB) are the most common performed procedures. Originally, bariatric procedures were described as purely restrictive, malabsorptive or combined restrictive-malabsorptive procedures limiting food intake and/or nutrient absorption. Nowadays, the anatomical alterations are known to affect the gastrointestinal physiology. Consequently, these changes affect the digestion and absorption of nutrients and drugs. Therefore, understanding the gastrointestinal physiology per se is crucial for the prevention of postoperative nutritional deficiencies and the optimization of postoperative drug therapy. In this review, we summarize the current knowledge on the impact of SG and RYGB on gastrointestinal physiology and bring attention to the knowledge gaps in the field. Concisely, available (pre)clinical research indicates that SG accelerates liquid and solid gastric emptying, accelerates small intestinal transit and increases bile acid serum levels. The effect on gastrointestinal acidity, gastric and pancreatic secretions, surface area and colonic transit remains largely unknown. Moreover, RYGB diminishes gastric acid secretion, accelerates liquid gastric emptying and increases bile acid serum levels. The effect on intestinal $\mathrm{pH}$, solid gastric emptying, intestinal transit time, gastric enzyme secretions and surface area remains largely unknown. 


\section{Introduction}

According to the last report of the World Health Organization, the obesity prevalence has tripled worldwide with 650 million adults having a body mass index (BMI) $\geq 30 \mathrm{~kg} / \mathrm{m}^{2}$ (1). Overweight and obesity are linked with a significant increase in all-cause mortality $(2,3)$. In parallel, the number of bariatric and metabolic surgery procedures has more than doubled worldwide (4). A lower rate of allcause-mortality and lower risk of obesity-related comorbidities after surgery justifies the increased interest. A recent meta-analysis observed a significant overall BMI loss of $13.53 \mathrm{~kg} / \mathrm{m}^{2}(95 \%$ confidence interval ( $\mathrm{Cl}): 11.55-15.51)$ and $11.40 \mathrm{~kg} / \mathrm{m}^{2}(95 \% \mathrm{Cl}: 5.28-28.08)$ at one and five years after surgery, respectively. Regarding morbidity, significant improvements occur in obesity-related comorbidities including diabetes, cardiovascular diseases, obstructive sleep apnoea, fertility and some types of cancer (5-8). Nonetheless, bariatric surgery can result in unintended adverse events (complication rate: $17.0 \%$ (95\% Cl: $11.0 \%-23.0 \%)(5)$. Potential benefits and complications are discussed in Appendix 1.

These consequences have redirected bariatric research towards the mechanism behind the resolution of obesity-related comorbidities, the potential complications and how to avoid them $(9,10)$. However, the original intention of surgery was to induce weight loss by restricting food intake and/or by introducing malabsorption through anatomical rearrangement (11-13). It is now understood that the anatomical alterations affect gastrointestinal physiology, whereby gut-brainendocrine and adipose-brain-endocrine signalling pathways that regulate hunger, satiation, satiety and nutrient metabolism are altered (14). By targeting the gastrointestinal tract, the delivery and concentration of (undigested) nutrients to the nutrient sensing enteroendocrine cells is affected. Thereby, the secretion of gut-derived hormones involved in appetite, satiety and motility regulation changes (14-17). Our understanding of the changes in gut-brain signalling pathways is increasing. However, it is important to recognize as well that the effect of the anatomical alterations on the gastrointestinal physiology per se plays a crucial role in determining outcomes after surgery, but is largely unknown (18). Gastrointestinal conditions influence both digestion and absorption of nutrients as well as the disintegration, dissolution and absorption of orally administered drugs $(19,20)$. An inherent risk of developing vitamin and mineral deficiencies is present after surgery (2125). Next to nutritional deficiencies, new and/or persisting obesity-related comorbidities after surgery require adequate dosing for optimal pharmacotherapy. Significant changes in pharmacokinetics of different drug classes have been observed, potentially leading to unfavourable results (e.g. sub-therapeutic or toxic) $(26,27)$. 
Knowledge of the adaptations in gastrointestinal physiology may contribute to the prevention of

114 postoperative nutritional deficiencies and optimize postoperative drug therapy. In this review, we

115 summarize the current knowledge on the impact of the anatomical alterations of bariatric and 116 metabolic surgery on the gastrointestinal physiology. We focus on gastrointestinal acidity, 117 gastrointestinal motility including gastric emptying time and transit times, gastrointestinal surface 118 area including the intestinal absorptive cells and the presence of transporters and receptors; and 119 gastrointestinal enzyme secretions after Sleeve Gastrectomy (SG) and Roux-en-Y Gastric Bypass 120 (RYGB). The search strategy and selection criteria of the discussed articles is added in Appendix 2.

\section{Sleeve Gastrectomy and Roux-en-Y Gastric Bypass}

122 Bariatric procedures have evolved throughout the years as discussed in Appendix 3. To date, SG and 123 RYGB are the most commonly performed procedures constituting respectively $47.0 \%$ and $35.3 \%$ of 124 performed procedures (4). The anatomical alterations of these procedures include the longitudinal 125 resection of the greater curvature of the stomach for SG (restriction), and the formation of a small 126 gastric pouch without a pylorus (restriction) and rerouting the small intestine for RYGB 127 (malabsorption). For SG, the longitudinal resection of the stomach starts on the greater curvature 128 between 3 to $6 \mathrm{~cm}$ proximal of the pylorus and the end of the Laterjet nerve up to the angle of His 129 and leaves a long tubular gastric sleeve $(28,29)$. Laparoscopic RYGB-procedures vary slightly 130 depending on the technique of the surgeon with regard to the anastomotic technique and limb 131 length. For RYGB, a small gastric pouch is formed by partitioning the stomach. The small intestine is 132 then rearranged into a $\mathrm{Y}$-configuration through the transection of the small intestine $30-50 \mathrm{~cm}$ below 133 the ligament of Treitz, where the distal end is anastomosed to the gastric pouch with the formation
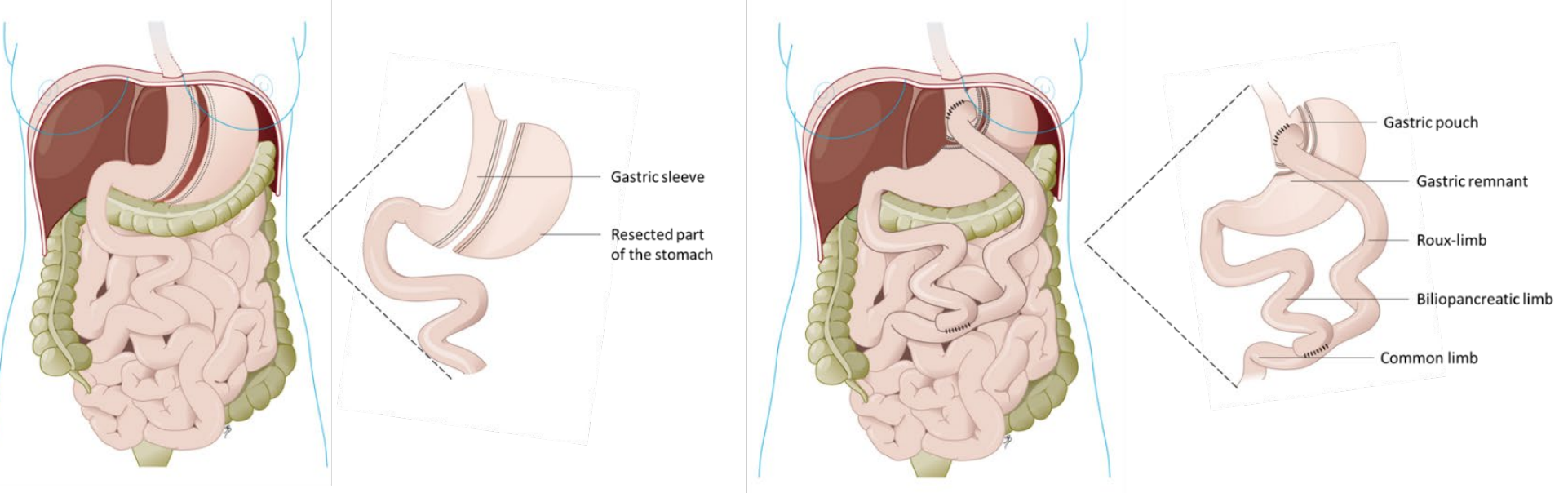

Figure 1: Laparoscopic Sleeve Gastrectomy (left) and Laparoscopic Roux-en-Y Gastric Bypass (right). of the alimentary or Roux-limb. The continuity of the proximal end is restored by a side to side 
jejunojejunal anastomosis and is called the biliopancreatic $\operatorname{limb}(28,29)$. Both procedures are visualised in Figure 1.

\section{Gastrointestinal acid secretion after Sleeve Gastrectomy and Roux-en-Y Gastric Bypass}

The stomach acts as a storage organ where ingested components are collected and mixed with gastric fluid consisting of gastric acid, enzymes, electrolytes and mucus. The oxyntic glands located in the fundus and corpus of the stomach regulate gastric acidity through the secretion of hydrochloric acid (gastric acid) via parietal cells resulting in a median gastric pH between 1.5 and 1.9 (20). Gastrin
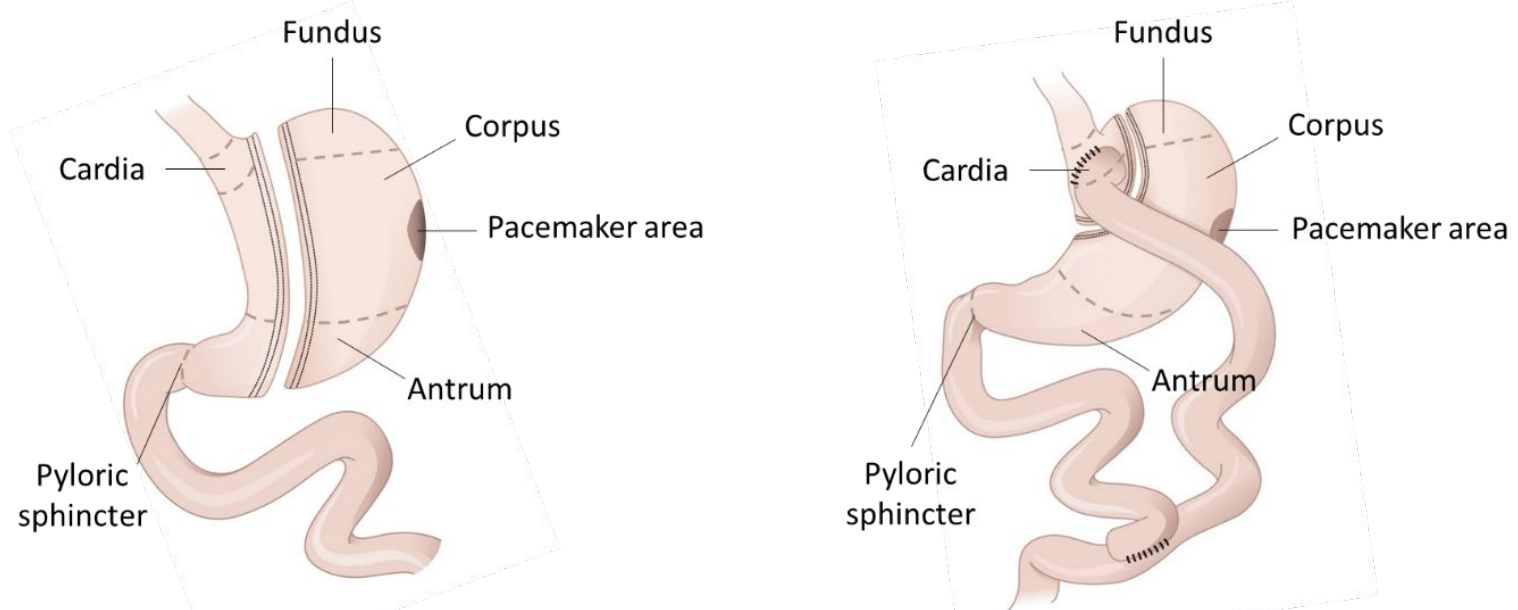

Figure 2: Anatomical regions of the sleeve (left) and the gastric pouch and remnant (right).

acts as a major stimulant of acid secretion, which is produced by the $G$ cells of the antrum (30). Theoretically, the formation of a small gastric pouch from the cardia, fundus and/or corpus and the separation of the remaining stomach through the gastric remnant may lead to the assumption that gastric acid secretion is diminished or absent in the pouch after RYGB (Figure 2).

Two human studies demonstrated the virtual absence of gastric acid secretion in the gastric pouch in basal and pentagastrin stimulated conditions in patients with RYGB $(31,32)$. Physiologically, the absence of gastric acid secretion resulted in a neutral environment $(\mathrm{pH}=7.0 \pm 0.2)$ in the proximal pouch of 37 RYGB patients, while the gastric remnant more or less conserved the expected acidity $(\mathrm{pH}=3.3 \pm 2.2)(33)$. Nonetheless, histological evaluation of gastric pouch mucosa in humans shows the presence of acid producing parietal cells (34). Furthermore, preclinical studies with RYGBoperated rats revealed an increased number of mucous neck cells and an increased number of larger parietal cells in the gastric pouch compared to sham-operated animals. Moreover, the parietal cells were characterized by a higher expression of the proton pump $\mathrm{H}^{+} / \mathrm{K}^{+}$ATPase, while gastrin positive cells appeared to be absent in pouch mucosa (35). It is plausible that the reduced acidity of the gastric juice in the remnant stimulates antral gastrin release. Consequently, increased gastrin levels 


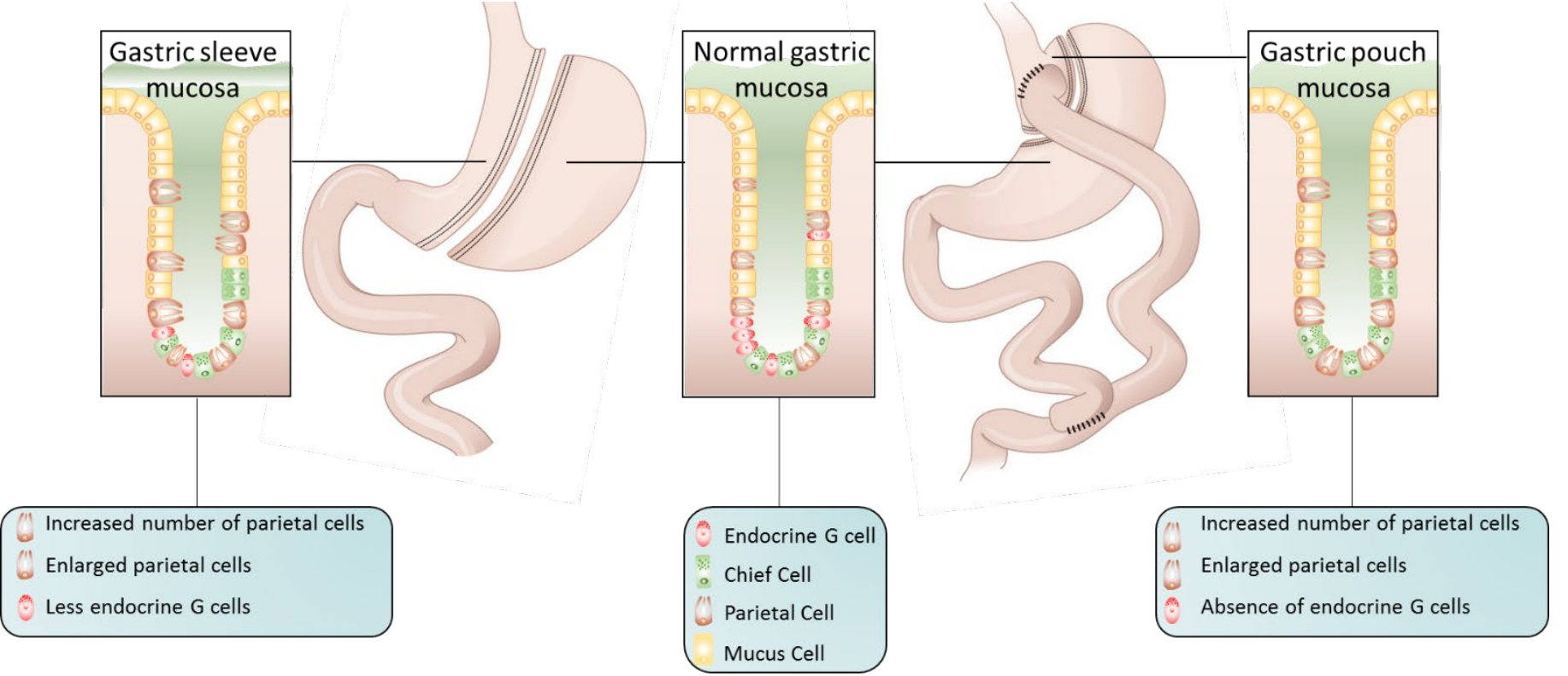

Figure 3: Potential gastric histological adaptations after Sleeve Gastrectomy (left) and Roux-en-Y Gastric Bypass (right). elevated in the gastric pouch. Some of these cells might redifferentiate into parietal cells and thereby partially explain parietal cells hyperplasia $(36,37)$. Altogether, these findings support the idea that the remaining pouch mucosa attempts (but partially fails) to fully recover the lost acid secretory capacities of the gastric remnant (Figure 3). However, direct interspecies extrapolation remains questionable.

In parallel, we assume that the formation of a gastric sleeve by resecting the greater curvature of the fundus, corpus and proximal antrum diminishes gastric acid secretion, but in a lesser amount as some acid-producing parietal and G cells are still present (Figure 2). Due to the absence of SG studies, clinical studies in patients with duodenal switch provide some first insights. Pre-pyloric pH monitoring during 24 hour indicated the preservation of the acidic gastric environment $(\mathrm{pH}: 2.66$ (Interquartile range of 1.74-5.81)) with an acidic $\mathrm{pH}<4$ measured during the majority of time $(68.7 \%)(38)$. Whether these findings can be directly translated to patients with a SG remains unsure due to the difference in surgical procedure. A duodenal switch consists of a vertical gastrectomy followed by bypassing a large portion of the small intestine (39). Noteworthy, animal studies have found contradictory findings regarding gastric sleeve morphology $(35,40)$. From a histological point of view, the gastric mucosa undergoes changes with increased numbers of mucous neck cells and increased numbers of enlarged parietal cells. While a significant reduction in number of antral $\mathrm{G}$ cells was observed compared to sham-operated rats $(40 \%$ vs. sham, $\mathrm{P}<0.01)(35)$. In line with the RYGB findings, it is plausible that the reduced acidity of the gastric juice elevates antral gastrin release and 
exert trophic effects on the parietal cells. In addition, the number of mucous neck cells is elevated in the gastric mucosa and some of these cells might redifferentiate into parietal cells $(36,37)$. Direct extrapolation to humans is not possible, but the loss of parietal cells could support the hypothesis that resecting the greater curvature partially diminishes gastric acid secretion (Figure 3).

Hereafter, the content of the gastric pouch or sleeve is emptied in the Roux limb or duodenum, respectively. In normal conditions, the gastric chyme is mixed in the duodenum with alkaline digestive juices containing bile, pancreatic and enteric secretions resulting in median $\mathrm{pH}$ values between 6.1 and 7.0 in fasted state (20). In the Roux limb, 24-hour pH measurement revealed a pH below 4 in 10.5\% (range: 0.3-37.7) of time at the level of the gastrojejunostomy (41). The discrepancy with the above-mentioned neutral $\mathrm{pH}$ of the gastric pouch emphasizes the need for additional studies to further elucidate $\mathrm{pH}$ levels. Furthermore, no information is available regarding $\mathrm{pH}$ values at the lower Roux-limb, biliopancreatic limb, common limb or colon. For gastric sleeve, post-pyloric $\mathrm{pH}$ monitoring during 24 hour in patients with a duodenal switch provides some first insights. Below the duodenoileostomy, a more or less neutral environment (5.79 (4.75-7.58)) was observed with an acidic $\mathrm{pH}<4$ measured during $13.0 \%$ (range: 0.0-34.6) of time. These findings suggest that the Brunner's glands located in the duodenal bulb neutralize the acidic content of the gastric sleeve via the secretion of alkaline mucus (38). Whether the buffering effect of the duodenal bulb neutralizes the acidic content in case of a SG remains to be understood.

\section{Gastrointestinal motility after Sleeve Gastrectomy and Roux-en-Y Gastric Bypass}

Gastrointestinal motility covers the interplay of smooth muscle contraction and relaxation within the gastrointestinal tract resulting in a predominant anterograde movement of the luminal content via peristaltic and non-peristaltic flow. Therefore, it controls the ability of the gastrointestinal tract to ingest, digest, transport and absorb nutrients from food and drugs.

\section{Effect on gastric emptying}

During meal intake, the fundus and upper corpus accommodate the ingested food through the relaxation of the proximal gastric wall without a significant increase in intragastric pressure. Relaxation of the gastric reservoir is mediated through vagovagal reflexes. After relaxation, tonic contractions shift the gastric content distally. In the midcorpus, peristaltic contraction waves arise from the gastric pacemaker activity, known as interstitial cells of Cajal, located along the greater curvature and proceed towards the pyloric sphincter. Forceful contractions result in the partial occlusion of the antrum. Pyloric contractions generate retropulsion of the gastric content towards the proximal stomach, thereby facilitating digestion through mixing with gastric secretions and mechanically breaking up solid particles to $<1$ to $2 \mathrm{~mm}$. Consequently, the pylorus relaxes and the 
digested content enters the duodenum during pyloric relaxation, referred to as gastric emptying. Both tonic and peristaltic muscular contractions are regulated by vagovagal reflexes and enteroendocrine hormones that accelerate (e.g. gastrin) or slow down gastric emptying (e.g. glucagon-like peptide 1 (GLP-1) and peptide YY (PYY)) (42,43). Theoretically, the resection of the fundus may increase intragastric pressure after SG due to the loss of relaxation and accommodation capacities. Furthermore, gastric contractile frequency may change as a result of the resection of the pacemaker area of the corpus. The distal nerve endings of the nervus vagus are transected, which might affect vagal signalling. In addition, the reduced gastric acidity might increase gastrin levels and affect the rate of emptying (44). Moreover, anatomical gastric remodelling may result in an accelerated emptying and rapid transit into the duodenum after SG (Figure 2). Different studies investigated pre- and postoperative gastric emptying of (semi-)solids using - the gold standard scintigraphy (Table 1) (45-54)(55). The majority of studies indicate that the time required for half of the (semi)-solid meal to leave the sleeve $\left(\mathrm{GET}_{1 / 2}\right)$ is significantly shorter up to two years after surgery (46-48,50-54). More specifically, pooled analysis revealed the tendency for SG to accelerate GET $_{1 / 2}$ of solids with 29.2 minutes $(95 \% \mathrm{Cl},-40.9$ to $-17.5 \mathrm{~min}$ ) at three months despite high heterogeneity $\left(I^{2}-91.4 \%\right)(56)$. In parallel, GET $_{1 / 2}$ of liquids is accelerated as well after SG (Table 1)(46,50). In order to elucidate the mechanism underlying accelerated $\mathrm{GE}$, a magnetic resonance imaging study investigated and revealed the preservation of antrum motility with an increasing antral fold speed. However, the proximal part of the sleeve lost peristalsis (57). Regarding vagovagal reflexes, a rodent study revealed sprouting of the nervus vagus afferents in the hindbrain after surgery (58). These findings might indicate a compensatory mechanism that overcomes the disruption of the distal nerve endings of the nervus vagus. Therefore, it is tempting to suggest that the elevated gastrin levels stimulate antral motility, resulting in accelerated emptying. Consequently, the rapid emptying of undigested nutrients leads to elevated levels of the satiety hormones GLP-1 and PYY. These hormones contribute to the efficacy of SG to improve and resolve obesity-associated comorbidities (reviewed elsewhere)(17).

For RYGB, the formation of a small gastric pouch without relaxation and accommodation capacities, a pacemaker area and a pylorus may lead to an accelerated emptying and rapid transit of nutrients into the jejunum (Figure 2). Moreover, the dorsal and ventral gastric branches of the nervus vagus are transected during pouch formation. These alterations will affect vagal signalling and may also contribute to the accelerated emptying. Gold standard scintigraphy studies reporting both pre-and postoperative $\mathrm{GET}_{1 / 2}$ of solids and liquids are absent. However, few studies investigated pre- and postoperative emptying using indirect methods. Paracetamol (acetaminophen) and $d$-xylose absorption tests indicate faster liquid emptying after surgery (59-63). Noteworthy, a more or less 
immediate maximal paracetamol plasma concentration is observed after surgery $(60,61)$.

246 Furthermore, multiple studies investigated postoperative pouch emptying or retention with/without

247 the comparison to stomach emptying of healthy controls using the gold standard scintigraphy (6469) (Table 2). For solids, Dirksen et al. observed accelerated pouch emptying in patients compared to controls (64). Other studies differed in outcome measurements, making comparison impossible

250

251

252

253

254 $(65,68,69)$. For liquids, Dirksen et al. and Nguyen et al. confirmed the accelerated liquid emptying of the absorption tests observed using scintigraphy $(64,67)$. To elucidate the mechanism underlying accelerated emptying, a study using high-resolution manometry revealed a moderately increased intraluminal pressure without a difference between the pouch and the Roux-limb. These findings suggest that the pouch and proximal Roux-limb may act as a common cavity (70). In addition, a rodent study observed differences in the anatomical integrity of the nervus vagus, which is suggestive for alterations in gut-brain communication. However, the precise role of the altered nervus vagus function in regulating gastric emptying after surgery remains unknown (14). Nonetheless, it is known that rapid emptying of undigested nutrients in the Roux-limb releases the satiety hormones GLP-1 and PYY and contributes to the efficacy of RYGB to improve and resolve obesity-associated comorbidities (reviewed elsewhere)(17).

\section{Effect on gastrointestinal transit time}

The small intestine acts as the major area for absorption, where peristalsis pushes luminal content in an aboral direction and segmentation causes mixing of the luminal content. These characteristics facilitate the contact of the luminal content with the mucosal absorptive cells, named enterocytes. Therefore, gastrointestinal residence time defines interaction time with both digestive enzymes, receptors and transporters $(42,71)$. Theoretically, the shorter gastric emptying time and therefore, the premature arrival of gastric content into the small intestine may accelerate intestinal transit for SG. Melissas et al. investigated the time between completion of a semisolid meal and the initiation of terminal ileum emptying into the caecum using scintigraphy (referred to as orocaecal transit time) pre- and postoperatively. The initiation of caecal filling was significantly delayed from 182 minutes (range: 120-275) to 210 minutes (range: 142-310) after surgery. In the same study, the small bowel transit time was significantly decreased from 71.8 minutes (range: 38-141) to 62.6 minutes (25-118) postoperatively (53). These findings are in line with Shah et al., who compared small bowel transit time of a solid meal in SG-patients (199.0 \pm 65.7 minutes) with small bowel transit time of healthy (298.1 \pm 9.2 minutes) and obese (281.5 \pm 46.2 minutes) controls using scintigraphy (72). All together, these (limited) findings might suggest that the gastrointestinal content reaches the terminal ileum faster, while arriving later at the caecum. The delay in caecal filling might result from changes in 
terminal ileal pressure, intracaecal pressure or changes in the ileocaecal valve tone, but the origin is currently unknown. Regarding colonic transit, no information is available for SG.

For RYGB, the bypass of the pylorus and the proximal small intestine may as well accelerate transit along the Roux-limb and the common limb. Morinigo et al. investigated pre- and postoperative orocaecal transit time in six subjects using a lactulose breath test (Preoperative: $115.0 \pm 22.4$ min; six weeks postoperative: $75.0 \pm 24.7 \mathrm{~min} ; P<0.05)(61)$. In addition, Nguyen et al. observed a significant faster caecal arrival time in ten RYGB patients compared to ten healthy controls using scintigraphy $(P<0.001)(67)$. While, Carswell et al. did not observe a significant difference in orocaecal transit time between seven RYGB patients and ten obese controls using a sulphasalazine absorption test (RYGB: 180 min (173-210); controls: $180 \min (150-240) ; P=0.935)(73)$. The data related to orocaecal transit time is more or less inconsistent, which could reflect the variation of techniques. The validity of the different absorption tests used in an altered gastrointestinal tract is questionable. In addition, Dirksen et al. observed a significant slower small bowel transit time of solids in patients compared to controls, while colonic transit did not differ between patients and controls (64). Altogether, available research on the effect of RYGB on gastrointestinal transit times is rather limited and inconsistent.

\section{Gastrointestinal secretions after Sleeve Gastrectomy and Roux-en-Y Gastric Bypass}

The gastrointestinal system secretes enzymes that initiate the enzymatic breakdown of meal components into smaller pieces for absorption(19,74).

\section{Effect on gastric enzyme secretions}

The effects of bariatric procedures on gastric acid secretion were already addressed in the third section of this review. Theoretically, stomach alterations could impair the secretion of gastric enzymes including pepsinogen and gastric lipase after bariatric surgery. Furthermore, the reduced gastric acid secretion may affect the conversion of inactive pepsinogen into active pepsin (maximal activity between $\mathrm{pH} 1.5$ to 2.5$)(75)$. Without active pepsin, protein molecules may remain intact and circumvent absorption. To date, human data is lacking regarding gastric secretion of lipase and pepsinogen after bariatric surgery. However, a decrease in serum pepsinogen 1 has been observed after RYGB and SG. Serum pepsinogen may reflect peptic secretion as a small amount of pepsinogen leaks into the bloodstream $(76,77)$. Despite a potential decrease in pepsinogen secretion that could affect protein digestion, Tessier et al. revealed an improved protein digestibility in RYGB-operated rats in comparison to SG-operated and sham-operated rats (78). Contrary to these findings, Gandarillas et al. observed a lower protein digestibility in RYGB-operated pigs in comparison to SGoperated pigs with ileal transposition and to sham-operated pigs. Furthermore, they observed as well 
a significant decrease in fat digestibility in RYGB-operated pigs in comparison to SG-operated pigs with ileal transposition and to sham-operated pigs (79). Although there is no comparable preclinical and no clinical data available whatsoever, these studies emphasize the lack of understanding regarding gastric enzyme secretion related to the digestibility of dietary protein and fat after bariatric surgery.

\section{Effect on pancreatic and gallbladder secretions}

After RYGB, the interaction of pancreatic enzymes and biliary secretions with the food bolus is delayed due to intestinal rearrangement. Bypassing the duodenum circumvents the initial contact between nutrients and the neuroendocrine cells that stimulate pancreatic and gallbladder secretion (80). Moreover, the presence of undigested food in the distal small intestine may trigger a higher secretion of ileal brake hormones (i.e. PYY, CCK and GLP-1) that inhibit secretion and motility to maximize absorption $(14,81)$. Recently, a lower secretion rate of trypsin, amylase and lipase was observed in common channel aspirates after infusion of a liquid meal in patients after RYGB compared to controls (82). These findings are in line with the reduced pancreatic secretion after a gastric bypass observed by Ito and Mason in 1971 (83). A reduced pancreatic secretion may affect the digestion of all macronutrients, culminating in the loss of nutrients for absorption. Besides affecting pancreatic secretion, different studies reported higher plasma bile acids $( \pm$ twofold increase) in fasted and fed state after RYGB (84-93). The increase was observed in both primary and secondary bile acids, yet the mechanism remains unknown. Higher serum levels may result from the accelerated contact of more undiluted bile acids with the ileum, leading to a more profound intestinal uptake and therefore, delivery to the liver. However, fasting plasma bile acids are also increased after SG, but to a lesser extent compared to RYGB $(85,93,94)$. Increases in circulating bile acid levels are known to activate the hepatic fibroblast growth factor 19 (FGF19) - fibroblast growth factor receptor 4 (FGFR4) signalling pathway. This pathway inhibits bile acid synthesis by suppressing the gene encoding hepatic cholesterol 7 $\alpha$-hydroxylase (CYP7A1), the rate-limiting enzyme of bile acid synthesis. Contrary to expectations, Flynn et al. observed that hepatic CYP7A1 expression was dramatically increased in a gastric bypass mouse model (95). Interspecies extrapolation remains unclear, but these findings support the idea that other factors may contribute to elevated circulating

338 bile acids in bariatric patients including altered biliary secretion, altered gut microbiota and dietary changes.

\section{Gastrointestinal surface area after Sleeve Gastrectomy and Roux-en-Y Gastric Bypass}

341 Key to the intestinal absorption of nutrients, electrolytes and solutes is a monolayer of intestinal 342 epithelial cells including absorptive enterocytes that line the inner surface of the intestine. The small 
intestine maximizes absorption through the organization of epithelial cells into crypts and villi, 344 resulting in an absorption area of approximately $32 \mathrm{~m}^{2}(96)$. Along the base of the crypts, multipotent 345 stem cell continuously give rise to a range of absorptive cells (e.g. enterocytes) and secretory cells 346 (e.g. goblet, enteroendocrine and paneth cells) that are characterized with a high cellular turnover 347 (3.48 \pm 1.55 days) $(20,97,98)$. In response to a variety of internal and external stimuli, the intestinal epithelium can undergo morphological and/or functional adaptations known as intestinal adaptation or enteroplasticity $(99,100)$. For instance, anatomical alterations and an altered nutrient supply may lead to remarkable morphological (i.e. hypertrophy/hyperplasia) or functional changes (i.e. altered proliferation or altered expression of receptors and/or transporters)(101).

\section{Effect on the intestinal absorptive cells}

353 For RYGB, the rapid delivery of (undigested) nutrients into the Roux-limb could induce 354 enteroplasticity to maintain maximal nutrient absorption. Likewise, the rapid delivery of (undigested) 355 nutrients to the duodenum and the potential affected gastrointestinal acidity may affect intestinal 356 absorptive cells to undergo morphological and functional changes after SG. To date, different preclinical and clinical studies have demonstrated some degree of enteroplasticity after different bariatric procedures (102-121). For RYGB, most rodent studies reported hypertrophy of the nutrientexposed limbs. Morphologically, the absorptive area expanded generally through an increase in the limbs' diameter, mucosal thickness, villus height and crypt depth. Epithelial proliferation increased at the level of the crypt $(102,103,105,106,109,116,119,121)$. Intestinal adaptation occurred maximally in the Roux-limb followed by the common limb and the colon (119). The disparity in morphological changes within the nutrient-exposed limbs highlights the potential of intestinal undigested nutrient exposure as a trigger for intestinal adaptation. This hypothesis is supported by the presence of hypertrophy in the nutrient exposed limbs and the presence of mucosal atrophy in the nutrient excluded area of rats with jejunoileal bypass (115). Nutrient exposure may therefore exert local effects on the mucosa as a compensatory mechanism to restore absorptive capacity of the compromised biliopancreatic limb. However, human studies reported contradictory findings of intestinal adaptation in the Roux-limb ranging from mild hypotrophy to no adaptations to hypertrophy $(106,110-113)$. Intestinal mechanisms of adaptations may vary between rodents and

371 humans, which highlights the need for additional clinical data for definitive conclusions. After SG, 372 there are no signs of cellular hyperplasia at the level of the duodenum, jejunum, corresponding to 373 the Roux-limb, or at the level of the ileum of rodents $(105,106)$. However, some studies reported signs of jejunal and ileal villus adaptations including increased villus height and width in combination with higher levels of crypt cell proliferation (104,106-108). By comparing RYGB and SG, these 
findings suggest that intestinal rearrangement is essential to obtain maximal intestinal adaptation.

377 Nonetheless, the lack of human studies makes it difficult to be conclusive.

378

379

380

381

382

383

\section{Effect on transporters and intestinal enzymes}

The majority of nutrients are absorbed along the small intestine, while the colon is predominantly responsible for water and electrolyte transport (42). Beyond nutrient transport, different enzymes and transporters are distributed along the small intestine for the metabolization and transport of drug compounds across the cell membrane (20). The complexity of functional adaptation with the invasive nature of the processes to assess adaptation underline the limited availability of human evidence. Functional adaptations have been shown to occur after bowel resection $(122,123)$. The extent of adaptation depends on the site of anatomical alteration, the presence of luminal nutrients and a variety of hormones and growth factors (i.e. human growth hormone and glucagon-like peptide 2) $(124,125)$. Given the intestinal rearrangement of bariatric surgery, we might assume that some degree of functional adaptation occurs especially after RYGB. For instance, a modified transporter expression could increase the absorptive capacity of the remaining nutrient exposed intestine to substantiate the bypassed biliopancreatic limb with its nutrient transporters or receptors
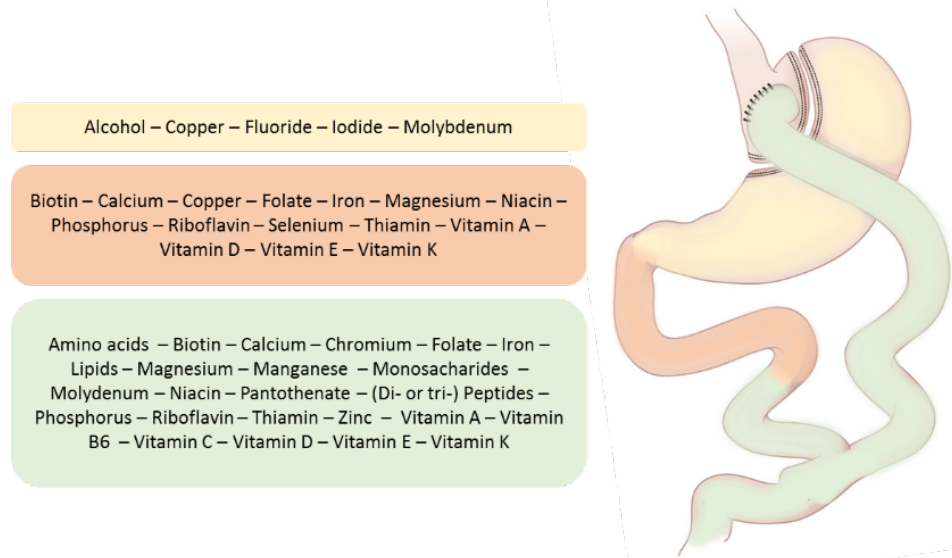

Figure 4: Macro- and micronutrient absorption sites along the gastrointestinal tract after Roux-en-Y Gastric Bypass.

391

392

(Figure 4).

Given the importance of type 2 diabetes research, a substantiate amount of research regarding functional adaption covers the field of glucose absorption after RYGB (106,116,121,126-128). Preclinical research in a porcine model detected a reduced intestinal glucose uptake in the Rouxlimb. A lower luminal sodium content in the Roux-limb, derived from the exclusion of sodium-rich bile, diminished glucose uptake via the apical SGLT1, but not its expression. Unexpectedly, the nonintestinal glucose transporter-1 (GLUT1) appeared at the basolateral side to potentially compensate the lack of luminal glucose (127). Interestingly, various non-clinical and clinical studies reported 
however an elevated intestinal glucose uptake in the Roux-limb $(106,126-128)$. Basolateral expression of GLUT1 in rodents and humans increased to the extent that expression levels were the second highest next to the brain. Glucose remained within the Roux-limb as a way to maintain their own cells energy requirements. Remarkably, the transporter-related adaptations are confined to the Roux-limb that is exposed to luminal nutrients, but not to pancreatic secretions. These findings might suggest that functional remodelling is triggered via undigested nutrient exposure. Expression of other glucose transporters including SGLT1, GLUT2, GLUT3 and GLUT5 remains controversial $(106,116,121,126-128)$. Contrary to the Roux-limb, no functional adaptation of any glucose transporter occurred in the jejunum after SG $(105,106)$. For micronutrients, the expression of the divalent metal transporter 1 (DMT1) for iron absorption has been observed to differ in the jejunal mucosa of the Roux-limb in patients after RYGB. Despite a decreased number of DMT1 along the jejunal mucosa, the expression increased in the cytoplasma of the enterocytes located in the apex of the villi of the jejunal mucosa. The authors hypothesize that morphological alterations induce the relocation of the enterocytes, leading to a higher number of DMT along the apex of the villi (111). No information is available regarding other transporters involved in the iron metabolism (e.g. ferroportin). Up to now, limited information is available regarding other transporters for micronutrient absorption after RYGB and SG.

Drug absorption may depend on the apical presence of the efflux transporter P-glycoprotein (P-gp), which facilitates the transport of substrates back into the intestinal lumen, and the presence of cytochrome P450 (CYP) enzymes, which facilitate the first-pass metabolism of drug compounds (e.g. CYP3A4 - the most abundant intestinal drug metabolising enzyme). Their expression varies along the different parts of the small intestine with an increasing expression of P-gp from the proximal to the distal small intestine, whereas the expression of CYP3A4 decreases towards the ileum (129-132). According to their distribution, the bioavailability of CYP3A4 substrates could increase due to the bypass of some CYP3A4 activity. On the other hand, the bioavailability of P-gp substrates could remain more or less unaltered as absorption may have occurred before they reach the distal part of the intestine where P-gp expression is higher (133). However, a large variability is observed in postoperative bioavailability of drugs that undergo first-pass metabolism by CYP3A4 and/or are P-gp substrates (133-137). In some cases, a higher dose of a drug is reported to be necessary to provide similar exposure as in non-bypass patients $(134,137)$. Others report that dose alterations cannot be generalized for all bariatric patients and every patient should be drug-specific monitored to prevent unfavourable sub-therapeutic or toxic results $(133,135)$. These opposing results underline the complexity of predicting CYP3A4 and/or P-gp substrates' bioavailability by solely relying on expression levels. The period of postoperative care remains essential as intestinal adaptation of P-gp 
expression may occur likewise other conditions (e.g. bowel resection) $(136,138,139)$. Other determining factors for expression include the low-grade inflammation related to obesity as well as CYP3A4 and/or P-gp genotype $(140,141)$.

Implications for nutrient and drug bioavailability after Sleeve Gastrectomy and Roux-en-Y Gastric Bypass

Lifelong nutritional monitoring is necessary after any bariatric procedure as gastrointestinal adaptations are not limited to the stomach. Dietary evaluation and laboratory screening for nutritional deficiencies should be an extensive, postoperative routine for all patients, particularly since patients have a higher risk to develop nutritional disorders than matched obese controls after bariatric surgery (142). The smaller pouch and sleeve reduces food and thus nutrient intake after surgery. Furthermore, dietary intolerance might contribute to a lower nutrient intake (143). The stomach requires an acidic environment for the initiation of protein digestion, releasing proteinbound vitamin B12, lipid digestion, optimising calcium solubility, optimising iron solubility and reducing iron into the absorbable ferrous form (144). By resecting or bypassing the oxyntic glands, it is thus plausible that digestion and/or absorption of these nutrients is affected. Moreover, the resection of the oxyntic glands results in an inadequate secretion of intrinsic factor from parietal cells, which is needed for vitamin B12 absorption further on in the ileum (145). In addition, accelerated pouch or sleeve emptying delivers nutrients rapidly into the small intestine that are partially undigested due to a reduction in gastric mixing. After RYGB, protein, carbohydrate and lipid digestion is further postponed until the ingested food reaches the pancreatic enzymes and biliary secretions in the common limb. Consequently, delaying lipid digestion may result in malabsorption of fat-soluble vitamins $A, D, E$ and $K$ that in turn affect the absorption of other nutrients (e.g. vitamin D - calcium interaction). Moreover, a major area for nutrient absorption with region-specific transporters is bypassed (Figure 4). More rapid absorption of ethanol has been observed after bariatric surgery, leading to higher and earlier maximum blood-ethanol concentration versus obese controls. Moreover, blood alcohol concentrations remain higher post-dosing. Altered ethanol kinetics might increase the risk for relapsing or developing new-onset alcohol use disorder and consequently, the risk of developing thiamine deficiency after surgery (146-149). In terms of laboratory screening for nutritional deficiencies, attention should be drawn to the definition of deficiencies with regard to the (combination of) diagnostic tests and associated cut-off values used. For accurate diagnosis, a list of preferred laboratory assays with their cut-off values should be proposed per nutrient. In case of nutritional deficiency, additional supplementation needs to be added to the standard postoperative supplementation regimen. The current regimen includes daily multivitamin and -mineral supplementation containing vitamin $B 1$, vitamin $B 12$, folate, vitamin $A$, vitamin $D$, vitamin $E$, vitamin 
$\mathrm{K}$, calcium, iron, zinc and copper. However, the available evidence supporting the current nutritional recommendations is graded as intermediate evidence (150).

Gastrointestinal physiology also affects drug bioavailability. For instance, gastric motility enhances disintegration of solid immediate release dosage forms. Gastric $\mathrm{pH}$ determines drug dissolution and solubility in case of pH-dependency, while gastric emptying is often the rate-limiting step of absorption. Intestinal motility results in the mixing of the intestinal content with pancreatic and biliary secretions, which enhances the interaction between the drug and the gastrointestinal surface area. Moreover, the intestinal transit time usually controls the absorption rate of low-solubility and low-permeability drugs as well as the release from modified release formulations. While the gastrointestinal surface area facilitates absorption, the presence of transporters may modulate absorption (20). Thus bariatric surgery can affect drug bioavailability at different levels depending on the drug's physiochemical properties, the drug product, and the type of surgery. For instance, an increase in serum thyroid-stimulating-hormone (TSH) concentrations has been observed after RYGB in patients receiving levothyroxine as a tablet formulation. After switching to a liquid formulation, a substantial decrease in serum TSH levels was observed. These findings may indicate a higher absorption from a liquid formulation as it circumvents the need for tablet disintegration and drug disintegration (151). Regarding elevated gastric $\mathrm{pH}$ after surgery, decreased solubility is expected for basic drugs, while an increased solubility is expected for acidic drugs. This may affect the rate and extent of absorption further down the intestinal tract. These assumptions are confirmed by the decrease in exposure of posaconazole (weak base) and the higher serum concentrations of furosemide (weak acid) observed after RYGB $(152,153)$. Additionally, the $T_{\max }$ of furosemide was significantly shorter, which may result from accelerated pouch emptying (153). After administration of an immediate- and controlled-release metoprolol formulation, a tendency towards a higher exposure was observed and suggest that there is no impact of an accelerated transit on modifiedrelease formulations. However, other mechanisms might overcome a reduced drug release. Metoprolol is metabolized by CYP2D9 that is expressed in the bypassed area. The first-pass metabolism may thus be bypassed and could contribute to a higher exposure due to a lower presystemic biotransformation (154). The bypass of the proximal small intestine delays the inlet of pancreatic enzymes and biliary secretions until the common limb. These changes might reduce the dissolution or solubility of lipophilic drugs. However, the exposure of the lipophilic drug fenofibrate was not altered after RYGB. These observations may result from a higher secretion of bile acids or from a comparable time between oral ingestion and bile acid contact due to accelerated pouch emptying (152). Clinical findings indicate that the rate or extent of drug absorption can increase, decrease or remain unaltered after surgery. Nonetheless, changes in drug absorption appear to be 
drug-specific, and the oral bioavailability of various drugs has been summarised in systematic reviews $(26,27,155)$. The biggest impact is observed for drugs that are intrinsically poorly absorbed, highly lipophilic or undergo enterohepatic recirculation. Therefore, clinicians and caregivers should be familiar with gastrointestinal alterations and their possible impact on oral drug bioavailability. Although the number of clinical studies is limited and SG may have a different effect to RYGB, a few theoretical considerations can be made based upon the gastrointestinal adaptations (155-159). First, a liquid formulation or crushing a solid formulation could circumvent lower absorption if impaired drug disintegration is expected. Second, lipophilic drugs are likely to be affected after RYGB as they depend on the solubilizing capacity created by bile salts. However, it is possible that other mechanisms compensate the expected reduction in absorption. Close monitoring of the patient for therapeutic effects and/or drug plasma levels is warranted. Third, there is little data available concerning the effect of bariatric surgery on modified-release formulations. From a hypothetical point of view, one might assume that the accelerated gastrointestinal transit may affect drug release from these formulations. Fourth, drugs that depend on cytochrome P450 enzymes may have a reduced first pass metabolism and a higher exposure. Finally, drugs with a narrow therapeutic window should be handled with caution, and therapeutic drug monitoring may be considered. Further studies are required to ensure the validity of the proposed measures.

\section{Future directions}

This review summarizes current knowledge regarding the effect of bariatric surgery on gastrointestinal physiology. Available data indicate an accelerated gastric emptying of solids and liquids, a faster small intestinal transit and an increase in bile acid serum levels after SG. Moreover, available data suggest that RYGB reduces gastric acid secretion, accelerates gastric emptying of liquids and increases bile acid serum levels \pm twofold. Despite the growing popularity of both procedures, important questions remain regarding gastrointestinal acidity, gastric and pancreatic secretions, surface area and colonic transit after SG and regarding intestinal $\mathrm{pH}$, solid gastric emptying, intestinal transit time, gastric enzyme secretions and surface area after RYGB . Especially, the field of SG requires more attention where the 'simplicity' of the anatomical procedure in comparison to RYGB has sometimes led to the belief of being less extreme in complication' type and incidence. Equal or greater importance is whether these gastrointestinal differences affect the patient's underlying condition or the susceptibility to adverse reactions. To respond, clinicians, caregivers and their patients need to be aware that the anatomical induced gastrointestinal alterations affect nutrient and drug bioavailability. However, novel and standardised approaches are necessary to further investigate the influence on nutritional and drug therapy to develop evidence- 
534 based guidelines with the sole goal of avoiding postoperative nutritional deficiencies or inefficient 535 drug dosing. 
537

538

539

540

541

542

543

544

545

546

547

548

549

550

551

552

553

554

555

556

557

558

559

560

561

562

563

564

565

566

567

568

Figures

- Figure 1: Laparoscopic Sleeve Gastrectomy (left) and Laparoscopic Roux-en-Y Gastric Bypass (right).

- Figure 2: Anatomical regions of the sleeve (left) and the gastric pouch and remnant (right).

- Figure 3: Potential gastric histological adaptations after Sleeve Gastrectomy (left) and Rouxen-Y Gastric Bypass (right).

- Figure 4: Macro- and micronutrient absorption sites along the gastrointestinal tract after Roux-en-Y Gastric Bypass.

Tables

- Table 1: Overview of Sleeve Gastrectomy studies investigating pre- and postoperative (semi-) solid and liquid gastric emptying using scintigraphy.

- Table 2: Overview of Roux-en-Y Gastric Bypass studies investigating (semi-) solid and liquid gastric emptying in patients and controls using scintigraphy.

\section{Contributors}

NS and CM conceptualised the review. NS performed the literature search, drafted the manuscript and adapted the figures. All authors contributed in their field of expertise and reviewed the article and approved the final version.

\section{Declaration of interest}

NS, TV, PA, JT, AM, ML, BVDS and CM declare no competing interest.

\section{Funding}

TV has received consulting fees from Takeda, VectivBio, Shire, Dr. Falk Pharma, Tramedico, Truvion and Zealand Pharma unrelated to writing the article, lecturing fees from Abbott, Kyowa Kirin, Menarini, Tramedico and Truvion unrelated to writing the article and research grants as a Senior Clinical Investigator Grant from Flanders Research Foundation (FWO Vlaanderen) unrelated to writing the article. PA has received consulting fees from UCB, Janssen Pharmaceutica and Prodigest, and research grants from Flanders Research Foundation (FWO Vlaanderen), Flanders Innovation and Entrepreneurship (VLAIO Vlaanderen Agentschap Innoveren \& Ondernemen), KU Leuven Internal Funds, Merck, Roche and S.M.B. Laboratories. JT has received consulting fees from AlfaWassermann, Allergan, Christian Hansen, Danone, Grünenthal, Ironwood, Janssen, Kiowa Kirin, Menarini, Mylan, Neutec, Novartis, Noventure, Nutricia, Shionogi, Shire, Takeda, Theravance, Tramedico, Truvion, Tsumura, Zealand and Zeria pharmaceuticals unrelated to writing the article, lecturing fees from Abbott, Allergan, AstraZeneca, Janssen, Kyowa Kirin, Menarini, Mylan, Novartis, Shire, Takeda, 
Truvion and Zeria unrelated to writing the article and research grants from Shire, Sofar and Tsumura unrelated to writing the article. AM has received consulting fees from Novo Nordisk, Sanofi, Merck Sharp \& Dome, AstraZeneca, Amgen, Aegerion Pharmaceuticals, and Fresenius Medical Care unrelated to writing the article and lecturing fees from Novo Nordisk, Sanofi, Eli Lilly, Amgen, AstraZeneca, Novartis, Boehringer Ingelheim, Merck Sharp \& Dome, and Johnson \& Johnson, unrelated to writing the article. ML has received lecturing fees from Medtronic. BVdS has received research grants as a Senior Clinical Investigator Grant from Flanders Research Foundation (FWO Vlaanderen) unrelated to writing the article. $\mathrm{CM}$ has received consulting fees from the Belgian Superior Health Council (HGR), the Belgian Federal Agency of the Safety of the Food Chain (FASFC), the International Life Sciences Institute Europe (ILSI Europe), Food Science and Law and the Belgian Nutrition Information Center (Nutrinews) unrelated to writing the article and research grants from Flanders Research Foundation (FWO Vlaanderen), Flanders Innovation and Entrepreneurship (VLAIO Vlaanderen Agentschap Innoveren \& Ondernemen), the EU Framework Programme for Research and Innovation named Horizon 2020 and the Flemish Interuniversity Council for Development Cooperation (VLIR- UOS) unrelated to writing the article and a research grant from KU Leuven Internal Fund related to writing the article.

\section{Acknowledgements}

We thank Myrthe Boymans for designing the illustrations of the Roux-en-Y Gastric Bypass and Sleeve Gastrectomy. The content is solely the responsibility of the authors and does not necessarily represent the official views of any funding body.

\section{References}

1. World Health Organisation. Obesity and overweight Fact Sheet. Available from: https://www.who.int/news-room/fact-sheets/detail/obesity-and-overweight [Accessed 19th January 2020].

2. Global BMI Mortality Collaboration, Di Angelantonio E, Bhupathiraju ShN, et al. Body-mass index and all-cause mortality: individual-participant-data meta-analysis of 239 prospective studies in four continents. Lancet. 2016;388(10046):776-786.

3. Aune D, Sen A, Prasad M, et al. BMI and all cause mortality: systematic review and non-linear dose-response meta-analysis of 230 cohort studies with 3.74 million deaths among 30.3 million participants. BMJ. 2016;353:i2156.

4. Ramos A, Kow L, Brown W et al. The IFSO Global Registry: 5th IFSO Global Registry Report. Available from: https://www.ifso.com/pdf/5th-ifso-global-registry-report-september2019.pdf. [Accessed 19th January 2020] 
5. Chang SH, Stoll CR, Song J, Varela JE, Eagon CJ, Colditz GA. The effectiveness and risks of bariatric surgery: an updated systematic review and meta-analysis, 2003-2012. JAMA Surg. 2014;149(3):275-287.

6. Wiggins T, Antonowicz SS, Markar SR. Cancer Risk Following Bariatric Surgery-Systematic Review and Meta-analysis of National Population-Based Cohort Studies. Obes Surg. 2019;29(3):1031-1039.

7. Maggard MA, Yermilov I, Li Z, et al. Pregnancy and fertility following bariatric surgery: a systematic review. JAMA. 2008;300(19):2286-2296.

8. Cardoso L, Rodrigues D, Gomes L, Carrilho F. Short- and long-term mortality after bariatric surgery: A systematic review and meta-analysis. Diabetes Obes Metab. 2017;19(9):12231232.

9. Reges O, Greenland P, Dicker D, et al. Association of Bariatric Surgery Using Laparoscopic Banding, Roux-en-Y Gastric Bypass, or Laparoscopic Sleeve Gastrectomy vs Usual Care Obesity Management With All-Cause Mortality. JAMA. 2018;319(3):279-90.

10. Jakobsen GS, Småstuen MC, Sandbu R, et al. Association of Bariatric Surgery vs Medical Obesity Treatment With Long-term Medical Complications and Obesity-Related Comorbidities. JAMA. 2018;319(3):291-301.

11. Hopkins J, Howes N, Chalmers K, et al. What are important outcomes of bariatric surgery? An in-depth analysis to inform the development of a core outcome set and a comparison between the views of surgeons and other health professionals (the BARIACT study). Lancet. 2015;385:Suppl 1:S43.

12. Wilkinson LH, Peloso OA. Gastric (Reservoir) Reduction for Morbid Obesity. Arch Surg. 1981;116(5):602-605.

13. Mason EE, Ito C. Gastric bypass in obesity. 1967. Obes Res. 1996;4(3):316-319.

14. Sinclair $P$, Brennan DJ, le Roux CW. Gut adaptation after metabolic surgery and its influences on the brain, liver and cancer. Nat Rev Gastroenterol Hepatol. 2018;15(10):606-624.

15. Ionut V, Burch M, Youdim A, Bergman RN. Gastrointestinal hormones and bariatric surgeryinduced weight loss. Obesity (Silver Spring). 2013;21(6):1093-1103.

16. Meek CL, Lewis HB, Reimann F, Gribble FM, Park AJ. The effect of bariatric surgery on gastrointestinal and pancreatic peptide hormones. Peptides. 2016;77:28-37.

17. Ochner CN, Gibson C, Shanik M, Goel V, Geliebter A. Changes in neurohormonal gut peptides following bariatric surgery. Int J Obes (Lond). 2011;35(2):153-166.

18. Vella A. Enteroendocrine secretion after Roux-en-Y gastric bypass: is it important? Neurogastroenterol Motil. 2013;25(1):1-3.

19. Goodman BE. Insights into digestion and absorption of major nutrients in humans. Adv Physiol Educ. 2010;34(2):44-53.

20. Vertzoni $M$, Augustijns $P$, Grimm $M$, et al. Impact of regional differences along the 
gastrointestinal tract of healthy adults on oral drug absorption: An UNGAP review. Eur J Pharm Sci. 2019;134:153-175.

21. Olbers T, Beamish AJ, Gronowitz E, et al. Laparoscopic Roux-en-Y gastric bypass in adolescents with severe obesity (AMOS): a prospective, 5-year, Swedish nationwide study. Lancet Diabetes Endocrinol. 2017;5(3):174-83.

22. Bal BS, Finelli FC, Shope TR, Koch TR. Nutritional deficiencies after bariatric surgery. Nat Rev Endocrinol. 2012;8(9):544-556.

23. Gletsu-Miller N, Wright BN. Mineral malnutrition following bariatric surgery. Adv Nutr. 2013;4(5):506-517.

24. Chakhtoura MT, Nakhoul N, AkI EA, Mantzoros CS, El Hajj Fuleihan GA. Guidelines on vitamin $D$ replacement in bariatric surgery: Identification and systematic appraisal. Metabolism. 2016;65(4):586-597.

25. Steenackers N, Van der Schueren B, Mertens A, et al. Iron deficiency after bariatric surgery: what is the real problem?. Proc Nutr Soc. 2018;77(4):445-455.

26. Yska JP, van der Linde S, Tapper VV, et al. Influence of bariatric surgery on the use and pharmacokinetics of some major drug classes. Obes Surg. 2013;23(6):819-825.

27. Padwal R, Brocks D, Sharma AM. A systematic review of drug absorption following bariatric surgery and its theoretical implications. Obes Rev. 2010;11(1):41-50.

28. Nguyen NT, Varela JE. Bariatric surgery for obesity and metabolic disorders: state of the art. Nat Rev Gastroenterol Hepatol. 2017;14(3):160-169.

29. Kaufman J, Billing J, Billing P. Laparoscopic Sleeve Gastrectomy. In: Preedy VR, Rajendram R, Martin C (eds.) Metabolism and Pathophysiology of Bariatric Surgery: Nutrition, Procedures, Outcomes and Adverse Effects. Elsevier 2016. p. 103-112.

30. Schubert ML. Gastric acid secretion. Curr Opin Gastroenterol. 2016;32(6):452-460.

31. Smith DC, Herkes SB, Behrns KE, Fairbanks VF, Kelly KA, Sarr MG. Gastric Acid Secretion and Vitamin B 12 Absorption After Vertical Ronx-en-Y Gastric Bypass for Morbid Obesity. Ann Surg. 1993;218(1):91-96.

32. Behrns KE, Smith CD, Sarr MG. Prospective evaluation of gastric acid secretion and cobalamin absorption following gastric bypass for clinically severe obesity. Dig Dis Sci. 1994;39(2):315-320.

33. Ishida RK, Faintuch J, Paula AMR, et al. Microbial flora of the stomach after gastric bypass for morbid obesity. Obes Surg. 2007;17(6):752-758.

34. Siilin $\mathrm{H}$, Wanders $\mathrm{A}$, Gustavsson $\mathrm{S}$, Sundbom $\mathrm{M}$. The proximal gastric pouch invariably contains acid-producing parietal cells in Roux-en-Y gastric bypass. Obes Surg. 2005;15(6):771-777.

35. Arapis K, Cavin JB, Gillard L, et al. Remodeling of the residual gastric mucosa after Roux-en-Y gastric bypass or vertical sleeve gastrectomy in diet-induced obese rats. PLoS One. 2015;10(3):e0121414. 
36. Dacha S, Razvi M, Massaad J, Cai Q, Wehbi M. Hypergastrinemia. Gastroenterol Rep (Oxf). 2015;3(3):201-208.

37. Karam SM. A focus on parietal cells as a renewing cell population. World J Gastroenterol. 2010;16(5):538-546.

38. Bekhali Z, Hedberg J, Hedenström H, Sundbom M. Large Buffering Effect of the Duodenal Bulb in Duodenal Switch: a Wireless pH-Metric Study. Obes Surg. 2017;27(7):1867-1871.

39. Mechanick JI, Youdim A, Jones DB, et al. Clinical practice guidelines for the perioperative nutritional, metabolic, and nonsurgical support of the bariatric surgery patient--2013 update: cosponsored by American Association of Clinical Endocrinologists, the Obesity Society, and American Society for Metabolic \& Bariatric Surgery. Endocr Pract. 2013;19(2):337-372.

40. Martín M, Burrell MA, Gómez-Ambrosi J, et al. Short- and long-term changes in gastric morphology and histopathology following sleeve gastrectomy in diet-induced obese rats. Obes Surg. 2012;22(4):634-640.

41. Hedberg J, Hedenström $\mathrm{H}$, Sundbom M. Wireless pH-metry at the gastrojejunostomy after Roux-en-Y gastric bypass: A novel use of the BRAVOTM system. Surg Endosc. 2011;25(7):2302-7.

42. Leung PS. The gastrointestinal system: Gastrointestinal, nutritional and hepatobiliary physiology. Springer, 2014.

43. Goyal RK, Guo Y, Mashimo H. Advances in the physiology of gastric emptying. Neurogastroenterol Motil. 2019;31(4):e13546.

44. el-Sharkawy TY, Szurszewski JH. Modulation of canine antral circular smooth muscle by acetylcholine, noradrenaline and pentagastrin. J Physiol. 1978;279:309-320.

45. Bernstine H, Tzioni-Yehoshua R, Groshar D, et al. Gastric emptying is not affected by sleeve gastrectomy--scintigraphic evaluation of gastric emptying after sleeve gastrectomy without removal of the gastric antrum. Obes Surg. 2009;19(3):293-298.

46. Kandeel AA, Sarhan MD, Hegazy T, Mahmoud MM, Ali MH. Comparative assessment of gastric emptying in obese patients before and after laparoscopic sleeve gastrectomy using radionuclide scintigraphy. Nucl Med Commun. 2015;36(8):854-862.

47. Melissas J, Koukouraki S, Askoxylakis J, et al. Sleeve gastrectomy - A restrictive procedure? Obes Surg. 2007;17(1):57-62.

48. Melissas J, Daskalakis M, Koukouraki S, et al. Sleeve gastrectomy - A "food limiting" operation. Obes Surg. 2008;18(10):1251-1256.

49. Pilone V, Tramontano S, Di Micco R, et al. Gastric emptying after sleeve gastrectomy: statistical evidence of a controlled prospective study with gastric scintigraphy. Minerva Chir. 2013;68(4):385-392.

50. Sista F, Abruzzese V, Clementi M, Carandina S, Cecilia M, Amicucci G. The effect of sleeve gastrectomy on GLP-1 secretion and gastric emptying: a prospective study. Surg Obes Relat Dis. 2017;13(1):7-14. 
51. Vives M, Molina A, Danús M, et al. Analysis of Gastric Physiology After Laparoscopic Sleeve Gastrectomy (LSG) With or Without Antral Preservation in Relation to Metabolic Response: a Randomised Study. Obes Surg. 2017;27(11):2836-2844.

52. Michalsky D, Dvorak P, Belacek J, Kasalicky M. Radical resection of the pyloric antrum and its effect on gastric emptying after sleeve gastrectomy. Obes Surg. 2013;23(4):567-73.

53. Melissas J, Leventi A, Klinaki I, et al. Alterations of global gastrointestinal motility after sleeve gastrectomy: A prospective study. Ann Surg. 2013;258(6):976-82.

54. Vigneshwaran B, Wahal A, Aggarwal S, et al. Impact of Sleeve Gastrectomy on Type 2 Diabetes Mellitus, Gastric Emptying Time, Glucagon-Like Peptide 1 (GLP-1), Ghrelin and Leptin in Nonmorbidly Obese Subjects with BMI 30-35.0 kg/m2: a Prospective Study. Obes Surg. 2016;26:2817-2823.

55. Keller J, Bassotti G, Clarke J, et al. Expert consensus document: Advances in the diagnosis and classification of gastric and intestinal motility disorders. Nat Rev Gastroenterol Hepatol. 2018;15(5):291-308.

56. Vargas EJ, Bazerbachi F, Calderon G, et al. Changes in Time of Gastric Emptying After Surgical and Endoscopic Bariatrics and Weight Loss: A Systematic Review and Meta-Analysis Clin Gastroenterol Hepatol. 2020;18(1):57-68.e5.

57. Baumann T, Kuesters S, Grueneberger J, et al. Time-resolved MRI after ingestion of liquids reveals motility changes after laparoscopic sleeve gastrectomy-preliminary results. Obes Surg. 2011;21(1):95-101.

58. Ballsmider LA, Vaughn AC, David M, Hajnal A, Di Lorenzo PM, Czaja K. Sleeve gastrectomy and roux-en-y gastric bypass alter the gut-brain communication. Neural Plast. 2015;2015:601985.

59. Stano S, Alam F, Wu L, et al. Effect of meal size and texture on gastric pouch emptying and glucagon-like peptide 1 after gastric bypass surgery. Surg Obes Relat Dis. 2017;13(12):197583.

60. Falkén Y, Hellström PM, Holst JJ, Näslund E. Changes in glucose homeostasis after Roux-en-Y gastric bypass surgery for obesity at day three, two months, and one year after surgery: Role of gut peptides. J Clin Endocrinol Metab. 2011;96(7):2227-2235.

61. Morínigo R, Moizé V, Musri M, et al. Glucagon-like peptide-1, peptide YY, hunger, and satiety after gastric bypass surgery in morbidly obese subjects. J Clin Endocrinol Metab. 2006;91(5):1735-1740.

62. Goday Arno A, Farré M, Rodríguez-Morató J, et al. Pharmacokinetics in Morbid Obesity: Influence of Two Bariatric Surgery Techniques on Paracetamol and Caffeine Metabolism. Obes Surg. 2017;27(12):3194-201.

63. Wang G, Agenor K, Pizot J, et al. Accelerated gastric emptying but no carbohydrate malabsorption 1 year after gastric bypass surgery (GBP). Obes Surg. 2012;22(8):1263-1267.

64. Dirksen C, Damgaard M, Bojsen-Møller KN, et al. Fast pouch emptying, delayed small intestinal transit, and exaggerated gut hormone responses after Roux-en-Y gastric bypass. 
65. Deden LN, Cooiman MI, Aarts EO, et al. Gastric pouch emptying of solid food in patients with successful and unsuccessful weight loss after Roux-en-Y gastric bypass surgery. Surg Obes Relat Dis. 2017;13(11):1840-1846.

66. Nguyen NQ, Debreceni TL, Bambrick JE, et al. Rapid gastric and intestinal transit is a major determinant of changes in blood glucose, intestinal hormones, glucose absorption and postprandial symptoms after gastric bypass. Obesity (Silver Spring). 2014;22(9):2003-2009.

67. Nguyen NQ, Debreceni TL, Burgstad CM, et al. Effects of Posture and Meal Volume on Gastric Emptying, Intestinal Transit, Oral Glucose Tolerance, Blood Pressure and Gastrointestinal Symptoms After Roux-en-Y Gastric Bypass. Obes Surg. 2015;25(8):1392-1400.

68. Nguyen NQ, Debreceni TL, Burgstad CM, et al. Effects of Fat and Protein Preloads on Pouch Emptying, Intestinal Transit, Glycaemia, Gut Hormones, Glucose Absorption, Blood Pressure and Gastrointestinal Symptoms After Roux-en-Y Gastric Bypass. Obes Surg. 2016;26(1):77-84.

69. Riccioppo D, Santo MA, Rocha M, et al. Small-Volume, Fast-Emptying Gastric Pouch Leads to Better Long-Term Weight Loss and Food Tolerance After Roux-en-Y Gastric Bypass. Obes Surg. 2018;28(3):693-701.

70. Björklund P, Lönroth H, Fändriks L. Manometry of the Upper Gut Following Roux-en-Y Gastric Bypass Indicates That the Gastric Pouch and Roux Limb Act as a Common Cavity. Obes Surg. 2015;25(10):1833-41.

71. Huizinga JD, Chen JH, Zhu YF, et al. The origin of segmentation motor activity in the intestine. Nat Commun. 2014;5:3326..

72. Shah S, Shah P, Todkar J, Gagner M, Sonar S, Solav S. Prospective controlled study of effect of laparoscopic sleeve gastrectomy on small bowel transit time and gastric emptying half-time in morbidly obese patients with type 2 diabetes mellitus. Surg Obes Relat Dis. 2010;6(2):152157.

73. Carswell KA, Vincent RP, Belgaumkar AP, et al. The effect of bariatric surgery on intestinal absorption and transit time. Obes Surg. 2014;24(5):796-805.

74. Gibney M, Vorster H, Kok F. Introduction to human nutrition. Oxford, United Kingdom; Blackwell Science Ltd; 2002.

75. Piper DW, Fenton BH. pH stability and activity curves of pepsin with special reference to their clinical importance. Gut. 1965;6(5):506-508.

76. Sillakivi T, Suumann J, Kirsimägi U, Peetsalu A. Plasma levels of gastric biomarkers in patients after bariatric surgery: biomarkers after bariatric surgery. Hepatogastroenterology. 2013;60(128):2129-2132.

77. Sundbom M, Mårdh E, Mårdh S, Ohrvall M, Gustavsson S. Reduction in serum pepsinogen I after Roux-en-Y gastric bypass. J Gastrointest Surg. 2003;7(4):529-535.

78. Tessier R, Ribeiro-Parenti L, Bruneau O, et al. Effect of different bariatric surgeries on dietary protein bioavailability in rats. Am J Physiol Gastrointest Liver Physiol. 2019;317(5):G592-G601. 
79. Gandarillas M, Hodgkinson SM, Riveros JL, Bas F. Effect of three different bariatric obesity surgery procedures on nutrient and energy digestibility using a swine experimental model. Exp Biol Med (Maywood). 2015;240(9):1158-1164.

80. Chandra R, Liddle RA. Neural and hormonal regulation of pancreatic secretion. Curr Opin Gastroenterol. 2009;25(5):441-446.

81. Barreto SG, Soenen S, Chisholm J, Chapman I, Kow L. Does the ileal brake mechanism contribute to sustained weight loss after bariatric surgery? ANZ J Surg. 2018;88(1-2):20-25.

82. O'Keefe SJD, Rakitt T, Ou J, et al. Pancreatic and Intestinal Function Post Roux-en-Y Gastric Bypass Surgery for Obesity. Clin Trans/ Gastroenterol. 2017;8(8):e112.

83. Ito C, Mason EE. Gastric bypass and pancreatic secretion. Surgery. 1971;69:526-532.

84. Pournaras DJ, Glicksman C, Vincent RP, et al. The role of bile after Roux-en-Y gastric bypass in promoting weight loss and improving glycaemic control. Endocrinology. 2012;153(8):3613-3619.

85. Steinert RE, Peterli R, Keller $\mathrm{S}$, et al. Bile acids and gut peptide secretion after bariatric surgery: A 1-year prospective randomized pilot trial. Obesity (Silver Spring). 2013;21(12):E660-E668.

86. Albaugh VL, Flynn CR, Cai S, Xiao Y, Tamboli RA, Abumrad NN. Early increases in bile acids post Roux-en- $Y$ gastric bypass are driven by insulin-sensitizing, secondary bile acids. J Clin Endocrinol Metab. 2015;100(9):E1225-E1233.

87. Patti ME, Houten SM, Bianco AC, et al. Serum bile acids are higher in humans with prior gastric bypass: Potential contribution to improved glucose and lipid metabolism. Obesity (Silver Spring). 2009;17(9):1671-1677.

88. Simonen $M$, Dali-Youcef $N$, Kaminska $D$, et al. Conjugated bile acids associate with altered rates of glucose and lipid oxidation after Roux-en-Y gastric bypass. Obes Surg. 2012;22(9):1473-1480.

89. Kohli R, Bradley D, Setchell KD, Eagon JC, Abumrad N, Klein S. Weight loss induced by Roux-en$\mathrm{Y}$ gastric bypass but not laparoscopic adjustable gastric banding increases circulating bile acids. J Clin Endocrinol Metab. 2013;98(4):E708-E712.

90. De Giorgi S, Campos V, Egli L, et al. Long-term effects of Roux-en-Y gastric bypass on postprandial plasma lipid and bile acids kinetics in female non diabetic subjects: A crosssectional pilot study. Clin Nutr. 2015;34(5):911-917.

91. Ahmad NN, Pfalzer A, Kaplan LM. Roux-en-Y gastric bypass normalizes the blunted postprandial bile acid excursion associated with obesity. Int $J$ Obes (Lond). 2013;37(12):1553-1559.

92. Dutia R, Embrey M, O'Brien CS, et al. Temporal changes in bile acid levels and $12 \alpha-$ hydroxylation after Roux-en-Y gastric bypass surgery in type 2 diabetes. Int $J$ Obes (Lond). 2015;39(5):806-813.

93. Nemati R, Lu J, Dokpuang D, Booth M, Plank LD, Murphy R. Increased Bile Acids and FGF19 
After Sleeve Gastrectomy and Roux-en-Y Gastric Bypass Correlate with Improvement in Type 2 Diabetes in a Randomized Trial. Obes Surg. 2018;28(9):2672-2686.

830

831

832

833

834

835

836

837

838

839

840

841

842

843

844

845

846

847

848

849

850

851

852

853

854

855

856

857

858

859

860

861

862

863

864

94. Khan FH, Shaw L, Zhang W, et al. Fibroblast growth factor 21 correlates with weight loss after vertical sleeve gastrectomy in adolescents. Obesity (Silver Spring). 2016;24(11):2377-2383.

95. Flynn CR, Albaugh VL, Cai S, et al. Bile diversion to the distal small intestine has comparable metabolic benefits to bariatric surgery. Nat Commun. 2015;6:7715.

96. Helander HF, Fändriks L. Surface area of the digestive tract-revisited. Scand J Gastroenterol. 2014;49(6):681-689.

97. Darwich AS, Aslam U, Ashcroft DM, Rostami-Hodjegan A. Meta-analysis of the turnover of intestinal epithelia in preclinical animal species and humans. Drug Metab Dispos. 2014;42(12):2016-2022.

98. Peterson LW, Artis D. Intestinal epithelial cells: Regulators of barrier function and immune homeostasis. Nat Rev Immunol. 2014;14(3):141-153.

99. Drozdowski LA, Clandinin MT, Thomson ABR. Morphological, kinetic, membrane biochemical and genetic aspects of intestinal enteroplasticity. World J Gastroenterol. 2009;15(7):774-787.

100. Le Gall M, Thenet S, Aguanno D, et al. Intestinal plasticity in response to nutrition and gastrointestinal surgery. Nutr Rev. 2019;77(3):129-143.

101. Scow JS, Tavakkolizadeh A, Zheng Y, Sarr MG. Acute "adaptation" by the small intestinal enterocyte: A posttranscriptional mechanism involving apical translocation of nutrient transporters. Surgery. 2011;149(5):601-605.

102. Le Roux CW, Borg C, Wallis K, et al. Gut hypertrophy after gastric bypass is associated with increased glucagon-like peptide 2 and intestinal crypt cell proliferation. Ann Surg. 2010;252(1):50-56.

103. Mumphrey MB, Patterson LM, Zheng $H$, Berthoud HR. Roux-en- $Y$ gastric bypass surgery increases number but not density of CCK-, GLP-1-, 5-HT-, and neurotensin-expressing enteroendocrine cells in rats. Neurogastroenterol Motil. 2013;25(1):e70-79.

104. Li L, Wang X, Bai L, et al. The effects of sleeve gastrectomy on glucose metabolism and glucagon-like peptide 1 in Goto-Kakizaki rats. J Diabetes Res. 2018; 2018:1082561.

105. Mumphrey MB, Hao Z, Townsend RL, Patterson LM, Berthoud HR. Sleeve Gastrectomy Does Not Cause Hypertrophy and Reprogramming of Intestinal Glucose Metabolism in Rats. Obes Surg. 2015;25(8):1468-1473.

106. Cavin JB, Couvelard A, Lebtahi R, et al. Differences in Alimentary Glucose Absorption and Intestinal Disposal of Blood Glucose after Roux-en-Y Gastric Bypass vs Sleeve Gastrectomy. Gastroenterology. 2016;150(2):454-464.

107. Myronovych A, Salazar-Gonzalez RM, Ryan KK, et al. The role of small heterodimer partner in nonalcoholic fatty liver disease improvement after sleeve gastrectomy in mice. Obesity (Silver Spring). 2014;22(11):2301-2311. 
108. Nausheen S, Shah IH, Pezeshki A, Sigalet DL, Chelikani PK. Effects of sleeve gastrectomy and ileal transposition, alone and in combination, on food intake, body weight, gut hormones, and glucose metabolism in rats. Am J Physiol Endocrinol Metab. 2013;305(4): E507-518.

109. Bueter M, Löwenstein C, Olbers T, et al. Gastric Bypass Increases Energy Expenditure in Rats. Gastroenterology. 2010;138(5): 1845-1853.

110. Casselbrant A, Elias E, Fändriks L, Wallenius V. Expression of tight-junction proteins in human proximal small intestinal mucosa before and after Roux-en-Y gastric bypass surgery. Surg Obes Relat Dis. 2015;11(1):45-53.

111. Marambio A, Watkins G, Castro F, et al. Changes in iron transporter divalent metal transporter 1 in proximal jejunum after gastric bypass. World J Gastroenterol. 2014;20(21):6534-6540.

112. Spak E, Björklund $\mathrm{P}$, Helander $\mathrm{HF}$, et al. Changes in the mucosa of the Roux-limb after gastric bypass surgery. Histopathology. 2010;57(5):680-688.

113. Nergård BJ, Lindqvist A, Gislason HG, et al. Mucosal glucagon-like peptide-1 and glucosedependent insulinotropic polypeptide cell numbers in the super-obese human foregut after gastric bypass. Surg Obes Relat Dis. 2015;11(6):1237-1246.

114. Ockander L, Hedenbro JL, Rehfeld JF, Sjölund K. Jejunoileal bypass changes the duodenal cholecystokinin and somatostatin cell density. Obes Surg. 2003;13(4):584-590.

115. Li B, Lu Y, Srikant CB, Gao ZH, Liu JL. Intestinal adaptation and Reg gene expression induced by antidiabetic duodenal-jejunal bypass surgery in Zucker fatty rats. Am J Physiol Gastrointest Liver Physiol. 2013;304(7):G635-645.

116. Taqi $E$, Wallace $L E$, de Heuvel $E$, et al. The influence of nutrients, biliary-pancreatic secretions, and systemic trophic hormones on intestinal adaptation in a Roux-en-Y bypass model. $J$ Pediatr Surg. 2010;45(5):987-95.

117. Habegger KM, Al-Massadi O, Heppner KM, et al. Duodenal nutrient exclusion improves metabolic syndrome and stimulates villus hyperplasia. Gut. 2014;63(8):1238-1246.

118. Kohli $\mathrm{R}$, Kirby $\mathrm{M}$, Setchell $\mathrm{KD}$, et al. Intestinal adaptation after ileal interposition surgery increases bile acid recycling and protects against obesity-related comorbidities. Am J Physiol Gastrointest Liver Physiol. 2010;299(3):G652-G660.

119. Hansen CF, Bueter M, Theis N, et al. Hypertrophy Dependent Doubling of L-Cells in Roux-en-Y Gastric Bypass Operated Rats. PLoS One. 2013;8(6):e65696.

120. Stock-Damgé C, Aprahamian M, Raul F, Marescaux J, Scopinaro N. Small-intestinal and colonic changes after biliopancreatic bypass for morbid obesity. Scand J Gastroenterol. 1986;21(9):1115-1123.

121. Stearns AT, Balakrishnan A, Tavakkolizadeh A. Impact of Roux-en-Y gastric bypass surgery on rat intestinal glucose transport. Am J Physiol Gastrointest Liver Physiol. 2009;297(5):G950957.

122. Ziegler TR, Fernández-Estívariz $\mathrm{C}, \mathrm{Gu}$ LH, et al. Distribution of the $\mathrm{H}+$ /peptide transporter PepT1 in human intestine: Up-regulated expression in the colonic mucosa of patients with 
short-bowel syndrome. Am J Clin Nutr. 2002;75(5):922-930.

904

905

906

907

908

909

910

911

912

913

914

915

916

917

918

919

920

921

922

923

924

925

926

927

928

929

930

931

932

933

934

935

936

937

938

939

123. Gouttebel MC, Saint Aubert B, Colette C, Astre C, Monnier LH, Joyeux H. Intestinal adaptation in patients with short bowel syndrome. Measurement by calcium absorption. Dig Dis Sci.1989;34(5):709-715.

124. Tappenden KA. Intestinal adaptation following resection. JPEN J Parenter Enteral Nutr. 2014;38(1 Suppl):23S-31S

125. Weale AR, Edwards AG, Bailey M, Lear PA. Intestinal adaptation after massive intestinal resection. Postgrad Med J. 2005;81(953):178-184.

126. Saeidi N, Meoli L, Nestoridi E, et al. Reprogramming of intestinal glucose metabolism and glycemic control in rats after gastric bypass. Science. 2013;341(6144):406-410.

127. Baud G, Daoudi $M$, Hubert $T$, et al. Bile diversion in roux-en-y gastric bypass modulates sodium-dependent glucose intestinal uptake. Cell Metab. 2016;23(3):547-553.

128. Nguyen NQ, Debreceni TL, Bambrick JE, et al. Upregulation of intestinal glucose transporters after Roux-en-Y gastric bypass to prevent carbohydrate malabsorption. Obesity (Silver Spring). 2014;22(10):2164-2171.

129. Drozdzik M, Gröer C, Penski J, et al. Protein abundance of clinically relevant multidrug transporters along the entire length of the human intestine. Mol Pharm. 2014;11(10):3547-3555.

130. Thelen K, Dressman JB. Cytochrome P450-mediated metabolism in the human gut wall. J Pharm Pharmacol. 2009;61(5):541-558.

131. Paine MF, Khalighi M, Fisher JM, et al. Characterization of interintestinal and intraintestinal variations in human CYP3A-dependent metabolism.J Pharmacol Exp Ther. 1997;283(3):1552-1562

132. Mouly S, Paine MF. P-Glycoprotein Increases from Proximal to Distal Regions of Human Small Intestine. Pharm Res. 2003;20(10):1595-1599.

133. Chan LN, Lin YS, Tay-Sontheimer JC, et al. Proximal Roux-en-Y gastric bypass alters drug absorption pattern but not systemic exposure of CYP3A4 and P-glycoprotein substrates. Pharmacotherapy. 2015;35(4):361-369.

134. Rogers CC, Alloway RR, Alexander JW, Cardi M, Trofe J, Vinks AA. Pharmacokinetics of mycophenolic acid, tacrolimus and sirolimus after gastric bypass surgery in end-stage renal disease and transplant patients: a pilot study. Clin Transplant. 2008;22(3):281-291.

135. Skottheim IB, Stormark K, Christensen H, et al. Significantly altered systemic exposure to atorvastatin acid following gastric bypass surgery in morbidly obese patients. Clin Pharmacol Ther. 2009;86(3):311-318.

136. Aron-Wisnewsky J, Lemaitre F, Clément $\mathrm{K}$, et al. Pharmacokinetics of immunomodulator treatments after roux-en-y bypass in obese patient. J Clin Pharmacol. 2013;53(7):779-784.

137. Brill MJ, van Rongen A, van Dongen EP, et al. The Pharmacokinetics of the CYP3A Substrate 
Midazolam in Morbidly Obese Patients Before and One Year After Bariatric Surgery. Pharm Res. 2015;32(12):3927-3936.

138. Ufer M, Häsler R, Jacobs G, et al. Decreased sigmoidal ABCB1 (P-glycoprotein) expression in ulcerative colitis is associated with disease activity. Pharmacogenomics. 2009;10(12):1941-1953.

139. Farrell RJ, Murphy A, Long A, et al. High multidrug resistance (P-glycoprotein 170) expression in inflammatory bowel disease patients who fail medical therapy. Gastroenterology. 2000;118(2):279-288.

140. Ulvestad M, Skottheim IB, Jakobsen GS, et al. Impact of OATP1B1, MDR1, and CYP3A4 Expression in liver and intestine on interpatient pharmacokinetic variability of atorvastatin in obese subjects. Clin Pharmacol Ther. 2013;93(3):275-282.

141. Hoffmeyer S, Burk O, von Richter O, et al. Functional polymorphisms of the human multidrugresistance gene: multiple sequence variations and correlation of one allele with $\mathrm{P}$ glycoprotein expression and activity in vivo. Proc Natl Acad Sci U S A. 2000;97(7):3473-3478.

142. Thereaux J, Lesuffleur T, Czernichow $\mathrm{S}$, et al. Long-term adverse events after sleeve gastrectomy or gastric bypass: a 7-year nationwide, observational, population-based, cohort study. Lancet Diabetes Endocrinol. 2019;7(10):786-795

143. Boerlage TC, van de Laar AW, Westerlaken S, Gerdes VE, Brandjes DP. Gastrointestinal symptoms and food intolerance 2 years after laparoscopic Roux-en- $Y$ gastric bypass for morbid obesity. Br J Surg. 2017;104(4):393-400.

144. Pohl D, Fox M, Fried M, et al. Do we need gastric acid?. Digestion. 2008;77(3-4):184-197.

145. Marcuard SP, Sinar DR, Swanson MS, Silverman JF, Levine JS. Absence of luminal intrinsic factor after gastric bypass surgery for morbid obesity. Dig Dis Sci. 1989;34(8):1238-1242.

146. Klockhoff H, Näslund I, Jones AW. Faster absorption of ethanol and higher peak concentration in women after gastric bypass surgery. Br J Clin Pharmacol. 2002;54(6):587-591.

147. Maluenda F, Csendes A, De Aretxabala X, et al. Alcohol absorption modification after a laparoscopic sleeve gastrectomy due to obesity. Obes Surg. 2010;20(6):744-748.

148. Parikh M, Johnson JM, Ballem N; American Society for Metabolic and Bariatric Surgery Clinical Issues Committee. ASMBS position statement on alcohol use before and after bariatric surgery. Surg Obes Relat Dis. 2016;12(2):225-230.

149. Oudman E, Wijnia JW, van Dam M, Biter LU, Postma A. Preventing Wernicke Encephalopathy After Bariatric Surgery. Obes Surg. 2018;28(7):2060-2068.

150. Parrott J, Frank L, Rabena R, Craggs-Dino L, Isom KA, Greiman L. American Society for Metabolic and Bariatric Surgery Integrated Health Nutritional Guidelines for the Surgical Weight Loss Patient 2016 Update: Micronutrients. Surg Obes Relat Dis. 2017;13(5):727-741.

151. Pirola I, Formenti AM, Gandossi E, et al. Oral liquid L-thyroxine (L-t4) may be better absorbed compared to L-T4 tablets following bariatric surgery. Obes Surg. 2013;23(9):1493-1496. 
152. Gesquiere I, Hens B, Van der Schueren B, et al. Drug disposition before and after gastric bypass: fenofibrate and posaconazole. Br J Clin Pharmacol. 2016;82(5):1325-1332.

153. Tandra S, Chalasani N, Jones DR, Mattar S, Hall SD, Vuppalanchi R. Pharmacokinetic and pharmacodynamic alterations in the Roux-en-Y gastric bypass recipients. Ann Surg. 2013;258(2):262-269.

154. Gesquiere I, Darwich AS, Van der Schueren B, et al. Drug disposition and modelling before and after gastric bypass: immediate and controlled-release metoprolol formulations. $\mathrm{Br} \mathrm{J}$ Clin Pharmacol. 2015;80(5):1021-1030.

155. Darwich AS, Henderson K, Burgin A, et al. Trends in oral drug bioavailability following bariatric surgery: examining the variable extent of impact on exposure of different drug classes. $\mathrm{Br} \mathrm{J}$ Clin Pharmacol. 2012;74(5):774-787

156. Hachon L, Declèves X, Faucher P, Carette C, Lloret-Linares C. RYGB and Drug Disposition: How to Do Better? Analysis of Pharmacokinetic Studies and Recommendations for Clinical Practice. Obes Surg. 2017;27(4):1076-1090.

157. Edwards A, Ensom MH. Pharmacokinetic effects of bariatric surgery. Ann Pharmacother. 2012;46(1):130-136.

158. Azran C, Wolk O, Zur M, et al. Oral drug therapy following bariatric surgery: an overview of fundamentals, literature and clinical recommendations. Obes Rev. 2016;17(11):1050-1066.

159. Miller $A D$, Smith KM. Medication and nutrient administration considerations after bariatric surgery. Am J Health Syst Pharm. 2006;63(19):1852-1857.

160. Maggard MA, Yermilov I, Li Z, et al. Pregnancy and fertility following bariatric surgery: a systematic review. JAMA. 2008;300(19):2286-2296.

161. Decker GA, Swain JM, Crowell MD, Scolapio JS. Gastrointestinal and nutritional complications after bariatric surgery. Am J Gastroenterol. 2007;102(11):2571-2581.

162. Payne JH, De Wind LT, Commons RR. Metabolic observations in patients with jejunocolic shunts. Am J Surg. 1963;106:273-289.

163. Welsh LK, Murayama KM. History of Bariatric Surgery. In: Chand B (ed) Endoscopy in Obesity Management. Springer Nature; 2018. p. 1-11.

164. Buchwald H. The evolution of metabolic/bariatric surgery. Obes Surg. 2014;24(8):1126-1135.

165. Buchald H, Varco R. Metabolic Surgery. New York: Grune and Stratton; 1978.

\section{Appendix 1: Benefits and complications of bariatric and metabolic surgery}

The percentage of postoperative remission for diabetes, hypertension and dyslipidaemia is $92.0 \%$ (Cl: 84.7-97.2\%), 75.2\% (Cl: 61.5-86.4\%) and 75.8\% (Cl: 55.6\%-91.5\%), respectively. Moreover, a postoperative remission rate of $96.2 \%$ (Cl: $86.7-99.8 \%$ ) is observed for obstructive sleep apnoea (5). 
1012

1013

1014

1015

1016

1017

1018

1019

1020

1021

1022

1023

1024

1025

1026

1027

1028

1029

1030

1031

1032

1033

1034

1035

1036

1037

1038

1039

1040

1041

1042

1043

1044

Regarding cancer incidence, bariatric surgery is associated with a significant reduction in overall (pooled odds ratio: $0.72 ; 95 \% \mathrm{Cl}: 0.59-0.87$ ) and obesity-related cancer incidence (pooled odds ratio: 0.55; 95\% Cl: 0.31-0.96). For women, a significant reduction in breast cancer incidence (pooled odds ratio: $0.50 ; 95 \% \mathrm{Cl}: 0.25-0.99$ ) is observed (6). Moreover, maternal and neonatal complications are less likely to occur for women who become pregnant after bariatric surgery in comparison to obese women who become pregnant (160). These findings support the fact that bariatric surgery is associated with a lower all-cause mortality (hazard ratio: 0.59; 95\% Cl: 0.52-0.67)(8).

Nonetheless, bariatric surgery can result in unintended adverse events (complication rate: 17.0\% (95\% Cl: $11.0 \%-23.0 \%)(5)$. A higher risk of hospital admission is observed in patients after surgery compared to matched controls due to gastrointestinal and nutritional disorders. Among nutritional disorders, iron deficiency and malnutrition are the most common (142). Other prevalent nutritional disorders include different nutritional deficiencies (e.g. calcium, vitamin D, vitamin B12, thiamine and folic acid), osteomalacia and dumping syndrome (161).

\section{Appendix 2. Search strategy and selection criteria}

References for this review were identified between Sept 1, 2019 and May 15, 2020 through searches of PubMed with the search terms "Gastric pH", "Gastric Acid Secretion", "Gastric Emptying", "Gastric Motility", "Intestinal Transit", "Transit Time", "Mucosa” “Epithelia”, “Pepsin”, "Pepsinogen”, "Pancreatic secretion", "Bile", “Enterocyte", “Enteroendocrine cells", "Enteroplasticity", "Cytochrome", "P-Glycoprotein", "Absorption", "Deficiency", "Pharmacokinetics" and "Bariatric Surgery" and were published between 1963 and 2020. Articles were also identified through searches of the authors' own files and snowball sampling (e.g. investigating the references of the search results). Papers published in English were reviewed. The final reference list was generated on the basis of originality and relevance to the broad scope of this review.

\section{Appendix 3. History of bariatric and metabolic surgery}

Originally, bariatric procedures were intended to induce weight loss with the first clinical research description in 1963. A jejunocolic bypass was performed in ten patients with 'uncontrolled' obesity, defined as at least 125 pounds (or $56.7 \mathrm{~kg}$ ) of overweight. The malabsorptive procedure included dividing the jejunum at 35 to $50 \mathrm{~cm}$ distal from the ligament of Treitz and establishing an end-to-side anastomosis to the proximal transverse colon. The procedure resulted in an average weight loss of 123 pounds (or $55.8 \mathrm{~kg}$ ). Nonetheless, a combination of electrolyte (e.g. $\mathrm{Ca}^{+}$and $\mathrm{K}^{+}$) imbalance and diarrhoea necessitated partial or complete restoral of gastrointestinal continuity (162). From then onwards, different bariatric procedures and techniques (e.g. surgical/laparoscopy) have been developed and technically refined to induce and sustain weight loss, while minimizing post-operative 
1045 morbidity and mortality $(28,163)$. Although the origin of these procedures focussed on the 1046 management of morbid obesity, benefits extend beyond weight loss (5-8) . The recognition of these 1047 benefits provided rationale for the emergence of the term metabolic next to bariatric surgery (164). 1048 Based on the definition of Henry Buchwald and Richard Varco, metabolic surgery refers to "the 1049 operative manipulation of a normal organ or organ system to achieve a biological result for a 1050 potential health gain"(165). 